\title{
mRNA Regulatory elements and bacterial virulence
}

\author{
Małgorzata Pawlikowska-Warych and Wiesław Deptuła \\ Department of Microbiology, Faculty of Biology, University of Szczecin, Szczecin, Poland
}

\begin{abstract}
Pathogenic bacteria cause many diseases, some of which are fatal. For researchers, it is a challenge to understand bacterial mechanisms of pathogenicity, including their virulence pathways regulated by RNA. This work presents data on the mechanisms of regulation and expression of several virulence factors coded by RNA, namely 5' UTR fragments, riboswitches and small non-coding RNA (sRNA).
\end{abstract}

Key words: RNA, 5'UTR, riboswitches, sRNA

Received: 03 June, 2013; revised: 19 December, 2013; accepted: 19 February, 2014; available on-line: 18 March, 2014

\section{INTRODUCTION}

During an infection, pathogenic bacteria must be capable of expressing their virulence genes, as this ensures their survival in the host's cells. Coordination of expression of the genes responsible for the virulence factors and environmental signals is the task of the so-called regulatory cascade. Such regulation involves many proteins and mRNAs that allow pathogens to adapt metabolically during an infection. Among the basic regulatory elements within mRNA, one can differentiate 5' UTR regulators, including RNA switches (riboswitches) and small non-coding RNAs (sRNAs) (Jaworski et al., 2005; Winkler \& Breaker 2005; Coppins et al., 2007). Although they are relevant to the biology of bacteria, it is still difficult to locate sRNA genes using genetic screening methods. At present, for finding these genes, bioinformatic methods and experimental validation are used $(\mathrm{Li}$ et al., 2012).

\section{5' UTR REGULATORS}

These RNA fragments are part of the untranslated regions at the $5^{\prime}$ end of mRNAs (5'UTRs), used by bacteria (unlike other organisms) to modify gene expression depending on the temperature, $\mathrm{pH}$, and presence of metabolites (riboswitches) (Winkler \& Breaker, 2005; Coppins et al., 2007; Gripenland et al., 2010). The 5'UTR region is located between starting point of transcription and the first codon in mRNA, and it is a region of varying length that contains several base pairs. The transcription process may occur on the basis of various promoters, which allows for the formation of many potential 5'UTR fragments (Loh et al., 2006). In pathogenic bacteria, they are used as factors that modify gene expression on the basis of structural changes induced by temperature, $\mathrm{pH}$ and the presence of metabolites.
It has been shown that bacteria possess a mechanism for temperature regulation that operates similar to proteins but at the nucleic acid level (DNA and RNA); thermal sensors most frequently operate at the RNA level and directly respond to changes in the temperature (Hurme \& Rhen, 1998). This mechanism is important to bacteria which need to change gene expression in response to the host's temperature and external environment. Such a mechanism was observed in Listeria monocytogenes, where the role of the thermal sensor is carried out by a 116-nucleotide 5' UTR fragment upstream of the prfA gene, encoding a sequence that forms additional secondary structures at lower temperatures and in turn is masking the SD sequence (responsible for attachment of the $30 \mathrm{~S}$ ribosome subunit) and thus is inhibiting translation. An alternative mRNA structure, which forms at $37^{\circ} \mathrm{C}$, uncovers the SD region and allows initiation of the translation process and subsequent formation of transcriptional regulator protein (PrfA) Johansson et al., 2002). PrfA is a necessary virulence factor in L. monocytogenes that activates expression of virulence genes that code for adhesive phagosomal escape factor (listerioly$\sin \mathrm{O})$ and a factor-modulating immunological response (Freitag et al., 2009). Also, in Yersinia pestis, a thermal sensor was found that controls the $\mathrm{LcrF}$ virulence factor expression. $\mathrm{LcrF}$ synthesis occurs exclusively at $37^{\circ} \mathrm{C}$ and in turn leads to activation of YopE expression, a protein that blocks phagocytosis, thereby increasing bacterial virulence (Fällman \& Gustavsson, 2005). In Shigella flexneri, promoter region of virF undergoes structural changes due to increased temperature (Falconi et al., 1998). VirF is a transcriptional activator of virulence genes, and the resulting changes in DNA conformation block binding of the histone-like nucleoid structuring protein (H-NS) that would otherwise repress transcription initiating from this promoter (Falconi et al., 1998). Similarly, in Salmonella typhimurium a thermal sensor was described, namely TlpA protein, that undergoes changes in the capacity of DNA binding in response to high temperature (Hurme et al., 1997). Another example is E. coli, where expression of the thermal shock factor $\sigma^{32}$ is controlled by thermal sensors encoded in the structural parts of the rpoH gene (Morita et al., 1999; de la Fuente et al., 2012). Analogous thermal sensors were also described for non-pathogenic bacteria (Altuvia et al., 1989; Servant \& Mazodier, 1996). For the first time this was recorded in bacteria after infection with bacteriophage $\lambda$, where no lysogenic process occurred due to the balance between two cIII

¿e-mail: kurp13@univ.szczecin.pl

Abbreviations: 5'UTR, untranslated region at 5' end of mRNA; SD, Shine-Dalgarno sequence; ROSE, repression of heat shock gene expression; HSP, heat shock proteins; c-di-GMP, cyclic di-guanosine monophosphate; QSS, quorum sensing system; Qrr, quorum regulatory; RNA, ribonucleic acid; mRNA, messenger RNA; sRNA, small non-coding RNA 
mRNA secondary structures (Altuvia et al., 1989). This phenomenon has been also described in Bradorbizobium japonicum, in which thermal sensors control the expression of HSP via ROSE structures, namely HSP repressive genes (Nocker et al., 2001), as well as in Streptomyces albus, in which thermal sensors control the hsp18 gene that encodes the HSP18 protein (Servant \& Mazodier 1996). The ROSE system appears to be widespread, as this thermosensor has been reported across many species of proteobacteria (de la Fuente et al., 2012).

In turn, gene expression control by changes in $\mathrm{pH}$ was described in Escherichia coli, where the alx gene encodes transporters engaged in immunity to tellurite (an antibacterial factor), the expression of which occurs in highly alkaline environments (Nechooshtan et al., 2009).

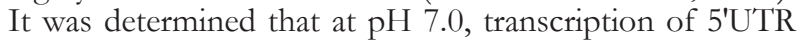
proceeds correctly, while in the case of an increased $\mathrm{pH}$, the formation of translation-inactive structures occurs, and RNA polymerase pauses in two different places on the 5'UTR as a result of the inactive proteins that are generated (Nechooshtan et al., 2009).

Other elements comprised of mRNA are RNA switches present within the 5'UTR region, referred to as riboswitches. They are present in Eubacteria, Archaea and some Eukaryotes (e.g. fungi, plants), which indicates their high biological importance (Nudler \& Mironov, 2004). In some bacteria riboswitches exist in high numbers, e.g. in Bacillus subtilis, they regulate 69 genes, which represents as much as $2 \%$ of the genome (Mandal et al., 2003). Their mechanism of action results from binding of particular ligands, which may include amino acids (e.g. lysine), nucleotides (e.g. guanine or adenine), or sugars (e.g. glucosamino-6-phosphate). This mechanism causes modification in the ligand biosynthesis or in expression of protein transport genes for such ligands. The binding of a ligand to a riboswitch causes structural changes to the riboswitch, which results in a change in the capacity of RNA polymerase to continue the transcription process or in the translation capacity of mRNA. Such binding occurs at the site referred to as a SD located at the UTR region, which is the point at which ribosome binds to the mRNA (Winkler \& Breaker 2005; Coppins et al., 2007; Gripenland et al., 2010). Also, some bacteria as Vibrio cholerae, Clostridium difficile and Bacillus cereus, use a riboswitch to sense cyclic di-GMPs (c-di-GMPs), whose concentration can regulate mobility and pathogenicity (Sudarsan et al., 2008). An example of negative regulation by c-di-GMP is a riboswitch situated upstream of the $g b p \mathrm{~A}$ gene, which codes for $\mathrm{N}$-acetyl-glucosaminebinding protein $A(G b p A)$, a protein important for $V i$ brio cholerae in the colonisation of human intestines (Kirn et al., 2005).

\section{SMALL NON-CODING RNAs}

sRNAs which are similar to riboswitches, occur in Eubacteria, Archea and eukaryotes and regulate many biological processes (Storz et al., 2005). In bacteria, sRNAs coordinate adaptation processes in response to environmental changes, integrate environmental signals and control gene expression (Wassarmann, 2002; Repoila et al., 2003; Gottesmann, 2004). sRNAs are usually 50-500 nucleotides long and undergo transcription but do not participate in the translation process (Kulkarini \& Kulkarini 2007). sRNAs regulate gene expression by interacting with mRNA, impacting RNA stability and thus affecting translation or by binding to proteins, which results in changing their function (Storz et al.,
2005). Participation of sRNAs in the control and regulation of pathogenicity was determined for e. g. in $S$. aureus (Huntzinger et al., 2005; Novick 2006), Pseudomonas aeruginosa (Heurlier et al., 2004; Sonnleitner et al., 2011), Erwinia carotovara subsp. carotovara (Liu et al., 1998), Vibrio cholerae (Miller et al., 2002) and Chlamydia trachomatis (Grieshaber et al., 2006). In the case of Staphylococcus aureus, virulence factors mainly include toxins, exoenzymes and surface proteins encoded by the agr system (Jaworski et al., 2005; Novick 2006). This system includes two different transcription units, RNAII and RNAIII, where RNAII encodes AgrA (a response regulator), AgrC (a kinase sensor), AgrD pro-peptide and AgrB peptidase, while RNAIII is the first sRNA described as a regulator and contains 514 nucleotides divided into 14 structures. RNAIII also encodes a 26-amino-acid $\delta$-haemolysin protein (Hld) and acts as a regulator of virulence (Novick, 2006). RNAIII is capable of binding to at least three fragments (targets) of mRNA: bla mRNA encoding $\alpha$-hemolysine, spa mRNA encoding protein $\mathrm{A}$ and rot mRNA encoding transcription factor Rot (Huntzinger et al., 2005). This agr-dependent expression of virulence factors is subject to periodical controls, as during bacterial cell growth adhesins are produced before haemolysins, proteases and degradation enzymes. This sequence of events is subject to various signals, e.g. together with an increasing number of $S$. aureus cells, the quantity of RNAIII increases, which results in the decreased expression of adhesins and activation of haemolysin translation (Novick 2006).

In Pseudomonas aeruginosa, pathogenicity is based on the regulation of Type III secretion system, properties of the biofilm and the level of N-Acyl homoserine, lactoneregulated exotoxins and secondary metabolites (Heurlier et al., 2004). The primary role is played by RsmA protein and small RNAs, named RsmY and RsmZ, which inhibit activity of the CsrA protein responsible for carbon metabolism. Furthermore, sRNAs are in charge of biofilm formation, quorum sensing and type III secretion (Heurlier et al., 2004; Chambers \& Sauer, 2013). Also, in Pseudomonas aeruginosa a small RNA named PhrS, activates translation of mRNA involved in quorum sensing (Sonnleitner et al., 2011). In Erwinia carotovora subsp. carotovora, RsmA protein and RsmB (sRNA molecule) also control the expression of several virulence factors, including pectolytic enzymes, proteases and cellulases, and they are responsible for quorum sensing (Liu et al., 1998). This regulation is related to control of the RsmA protein concentration, leading to degradation of $\mathrm{mRNA}$ of the virulence genes, which then bind to the RsmB protein (Jaworski et al., 2005). Vibrio cholerae, a bacterium generally present in the aquatic environment and pathogenic to mammals, has the capacity to adapt to various ecological niches, owing to multiple quorum sensing systems (QSSs) and seven sRNAs that control virulence and biofilm formation (Miller et al., 2002). The main elements regulating virulence include Qrr1-4, which acts via LuxO and LuxU (kinases responsible for luminescence), although the mechanism is still under research (Miller et al., 2002). Also, in Chlamydia trachomatis, IhtA sRNA controls the development cycle, which is regulated by two histone-like proteins, Hc1 and Hc2a (Grieshaber et al., 2006). In this bacterium, upon transformation of an elementary body (EB) into a reticular body (RB) inside the infected cell, the levels of IhtA sRNA increase and Hc1 protein synthesis decreases. The reverse situation takes place in the case of transformation of a RB into an EB (decrease in IhtA sRNA level, synthesis of Hc1 protein) (Grieshaber et al., 2006). Last year, a new chaperon, Hfq, 
was identified in Burkholderia cenocepacia, which is involved in this bacterium's pathogenicity (Ramos et al., 2013).

\section{CONCLUSION}

The data presented hereindicate that the RNA virulence factor regulation pathway is common, and regulation of the expression of genes that code for virulence factors depends on temperature and changes in $\mathrm{pH}$. This mechanism is important for intra-cellular bacteria, such as Listeria monocytogenes and Yersinia pestis, which are also present in the external environment. After entering the human body at a temperature of $37^{\circ} \mathrm{C}$, they start producing virulence factors (listeriolysin $\mathrm{O}, \mathrm{LcrF}$ ). Another regulation involves riboswitches that after binding to a ligand affect protein translation; this happens in bacteria including Vibrio cholerae, Clostridium difficile and Bacillus cereus. Also, by binding to mRNA, small non-coding RNAs (sRNAs), affect the formation of toxins or enzymes in Staphylococcus aureus, Erwinia carotovara, Pseudomonas aeuroginosa and Vibrio cholerae, while in Chlamydia trachomatis, they control the development cycle. Hence, it may be concluded that the mechanism regulating virulence in bacteria is an important element of the biology of pathogenic bacteria, as well as an interesting field for researchers, as the study of RNA's role in virulence may serve in the development of new methods of protection against such microbes.

\section{REFERENCES}

Altuvia S, Kornitzer D, Teff D, Oppenheim AB (1989) Alternative mRNA structures of the cIII gene of bacteriophage $\lambda$ determine the rate of its translational initiation. J Mol Biol 210: 365-280.

Chambers JR, Sauer K (2013) Small RNAs and their role in biofilm formation. Trends in Microbiology 21: 39-49.

Coppins RL, Hall KB, Groismann EA (2007) The intricate world of riboswitches. Curr Opin Microbiol 10: 176-181.

Falconi M, Colonna B, Prosseda G, Micheli G, Gualerzi CO (1998) Thermoregulation of Shigella and Escherichia coli EIEC pathogenicity. A temperature-dependent structural transition of DNA modulates accessibility of virF promoter to transcriptional repressor H-NS. EMBO J 17: 7033-7043.

Fällman M, Gustavsson A (2005) Cellular mechanisms of bacterial internalization counteracted by Yersinia. Int Rev Cytol 246: 135-188.

Freitag NE, Port GC, Miner MD (2009) Listeria monocytogenes - from saprophyte to intracellular pathogen. Nature Rev Microbiol 7: 623-628.

Fuente de la M, Valera S, Martinez-Guitarte JL (2012) ncRNAs and thermoregulation: A view in prokaryotes and eukaryotes. FEBS Letters 586: 4061-4069

Gottesmann S (2004) The small RNA regulators of Escherichia coli: roles and mechanisms. Annu Rev Microbiol 58: 303-328.

Grieshaber NA, Grieshaber SS, Fischer ER, Hackstadt T (2006) A small RNA inhibits translation of the histone-like protein Hc1 in Chlamydia trachomatis. Mol Microbiol 59: 541-550.

Gripenland J, Netteling S, Loh E, Tiensuu T, Toledo-Arana A, Johansson J (2010) RNAs: regulators of bacterial virulence. Nature Rev Microbiol 8: 857-866.

Heurlier K, Williams F, Heeb S, Dormond C, Pessi G, Singer D, Camara M, Williams P, Haas D (2004) Positive control of swarming, rhamnopolipid synthesis, and lipase production by the posttranscriptional RsmA/RsmZ system in Pseudomonas aeuroginosa PAO1. J Bacteriol 186: 2936-2945.

Huntzinger E, Boisset S, Saveanu C, Benito Y, Geissmann T, Namane A, Lina G, Etienne J, Ehresmann B, Ehresmann C, Jacquier A,
Vandenesch F, Romby P (2005) Staphylococcus aureus RNAIII and the endoribonucelase III coordinately regulate spa gene expression. EMBO J 24: 824-835.

Hurme R, Berndt KD, Normark SJ, Rhen M (1997) A proteinaceous gene regulatory thermometer in Salmonella. Cell 90: 55-64.

Hurme R, Rhen M (1998) Temperature sensing in bacterial gene regulation - what it all boils down to. Mol Microbiol 30: 1-6.

Jaworski A, Dobrowolska A, Stączek P (2005) RNA may control expression of several genes and metabolic pathways in bacterial cells. Post Mikerobiol 22: 89-98.

Johansson J, Mandin P, Renzoni A, Chiaruttini C, Springer M, Cossart P (2002) A RNA thermosensor controls expression of virulence genes in Listeria monocytogenes. Cell 110: 551-561.

Kirn TJ, Jude BA, Taylor RK (2005) A colonization factor links Vibrio cholerae environmental survival and human infection. Nature 438: 863-866.

Kulkarini RV, Kulkarini PR (2007) Computational approaches for the discovery of bacterial small RNAs. Methods 43: 131-139.

Li W, Ying X, Lu Q, Chen L (2012) Predicting sRNAs and their targets in bacteria. Genomics Proteomics Bioinformatics 10: 276-284.

Liu Y, Cui Y, Mukherjee A, Chatterjee AK (1998) Characterization of a novel RNA regulator of Erwinia carotovora ssp. carotovora that controls production of extracellular enzymes and secondary metabolites. Mol Microbiol 29: 219-234.

Loh E, Gripenland J, Johansson J (2006) Control of Listeria monocytogenes virulence by 5'-untranslated RNA. Trends Microbiol 14: 294 298.

Mandal M, Boese B, Barrick JE, Winkler WC, Breaker RR (2003) Riboswitches control fundamental biochemical pathways in Bacillus subtilis and other bacteria. Cell 113: 577-586.

Miller MB, Skorupski K, Lenz DH, Taylor RK, Bassler BL (2002) Parallel quorum sensing systems converge to regulate virulence in $\mathrm{Vi}$ brio cholera. Cell 110: 303-314.

Morita MT, Tanaka Y, Kodama TS, Kyogoku Y, Yanagi H, Yura T (1999) Translational induction of heat shock transcription factor $\sigma^{32}$ : evidence for a built-in RNA thermosensor. Genes Dev 13: 655-665.

Nechooshtan G, Elgrably-Weiss M, Sheaffer A, Westhof E, Altuvia S (2009) A pH-responsive riboregulator. Genes Dev 23: 2650-2662.

Nocker A, Hausherr T, Balsiger S, Krstulovic NP, Hennecke H, Narberhaus F (2001) A mRNA-based thermosensor controls expression of rhizobial heat shock genes. Nucleic Acids Res 29: 4800-4807.

Novick RP (2006) Staphylococcal pathogenesis and pathogenicity factors: genetics and regulation. In Gram positive pathogens, 2 edn. Fischetti A, Novick RP, Feretti J, Portnoy D, Rood J, eds, pp 496516. ASM Press, Washington, D.C.

Nudler E, Mironov AS (2004) The riboswitch control of bacterial metabolism. Trends Biochem Sci 29: 11-17.

Ramos CG, Grilo AM, da Costa PJP, Leităo JH (2013) Experimental identification of small non-coding regulatory RNAs in the opportunistic human pathogen Burkholderia cenocepacia J2315. Genomics 101: 139-148.

Repoila F, Majdalani N, Gottesman S (2003) Small non-coding RNAs, co-ordinators of adaptation processes in Escherichia coli: the RpoS paradigm. Mol Microbiol 48: 855-861.

Servant P, Mazodier P (1996) Heat induction of hsp18 gene expression in Streptomyces albus G: transcriptional and posttranscriptional regulation. I Bacteriol 178: 7031-7036.

Sonnleitner E., Gonzalez N, Sorger-Domenigg T, Heeb S, Richter AS, Backofen R, Williams P, Hüttenhofer A, Haas D, Bläsi U (2011) The small RNA PhrS stimulates synthesis of the Pseudomonas aeruginosa quinolone signal. Mol Microbiol 80: 868-885

Storz G, Altuvia S, Wassarmann KM (2005) An abundance of RNA regulators. Annu Rev Biochem 74: 199-217.

Sudarsan N, Lee ER, Weinberg Z, Moy RH, Kim JN, Link KH, Breaker RR (2008) Riboswitches in Eubacteria sense the second messenger cyclic Di-GMP. Science 321: 411-413.

Wassarmann KM (2002) Small RNAs in bacteria: diverse regulators of gene expression in response to environmental changes. Cell 109: $141-144$.

Winkler WC, Breaker RR (2005) Regulation of bacterial gene expression by riboswitches. Annu Rev Microbiol 59: 487-517. 